ISBN 978-81-934174-2-3

6th International Conference on Urban Design, Transportation, Architectural and Environmental

Engineering (UTAEE-17)

Istanbul (Turkey) Sept. 8-10, 2017

\title{
Cycling Policies and Strategies: The Case of Lisbon
}

\author{
João Marrana $^{1} \&$ Francisco Serdoura ${ }^{1}$ \\ ${ }^{1}$ CIAUD - Centro de Investigação em Arquitetura, Urbanismo e Design. \\ Faculdade de Arquitetura, Universidade de Lisboa. \\ Rua Sá Nogueira, Pólo Universitário, Alto da Ajuda, 1349-063 Lisboa, Portugal \\ jcdmarrana@fa.ulisboa.pt \& fs@fa.ulisboa.pt
}

\begin{abstract}
The paper's aims to contribute with a critical review on the meanings and particularities of cycling policies and measures, focusing on their categories, nature, implementation procedure and levels of operability, while exploring their role in the 'near future' of urban mobility. A general review of published studies on existent procedures, which influence bicycle usage, is presented recurring to contemporary peer-reviewed and 'grey' literature. To illustrate the paper's findings and argument, a case study is presented explaining Lisbon's cycling network. Preliminary findings suggest that cycling policies can be described as a set of programs developed with the intent of establishing direct and indirect rules and actions, envisioning the increase of cycling. They have different categories (physical, soft, complementary and knowledge), vary in both nature (push and pull measures) and implementation procedures (short-run and long-run), being particularly effective when implemented at a Municipal level. It can be argued that cycling policies and strategies play a key role in the promotion of cycling in urban transportation. The paper also supports that the success of bicycle usage in cities is strongly dependent on both political will and resolve and on a comprehensive approach, one that provides a coordinated and integrated package of cross-cutting multi-level policies and measures.
\end{abstract}

Keywords: Cycling, Policy, Urban, Lisbon.

\section{Introduction}

The role of policies and strategies in promoting bicycle usage as urban transportation is a key subject regarding the near future of sustainable mobility in large cities. The paper's aim is to contribute with a critical review on the meanings and particularities of cycling policies and strategies, focusing on their categories, nature, implementation procedure and levels of operability, while exploring their role in the 'near future' of urban transportation. Therefore, a systematic review of contemporary peer-reviewed literature was conducted, regarding policies, strategies and measures influencing cycling network development in urban areas. An analysis of 'grey' literature was also conducted, focusing on data published by independent agencies and multi-level government authorities in Europe. To illustrate the paper's findings and argument a case study is presented, explaining and describing Lisbon's cycling network, namely its evolution, hierarchy, route typology and considered policies and measures. The research method focused on qualitative data, namely policies, strategies and measures influencing bicycle provision and analysis of infrastructural solutions and promotional programs concerning bicycle commuting development, including Lisbon's bicycle network layout. Exploratory interviews were also conducted with the Municipality's advisory and technical staff responsible for the network development and overseeing. The findings suggest that 'cycling policies' can be defined as a package of programmes and measures, used both by public authorities and private stakeholder's, establishing direct and indirect strategies, actions and rules of procedure to increase and encourage cycling as a secure, comfortable and attractive mobility solution, regardless of its purpose. Results also suggest that cycling policies and strategies have different categories (physical, soft, complementary and knowledge), various natures (push and pull) and 
dissimilar implementation procedures (short-run and long-run) being particularly effective when executed at local levels. Thus, it can be argued that cycling policies and strategies play a key role in the promotion of cycling as urban transportation and that although there are many ways to increase cycling each city's situation is unique and requires a tailored mix of policies and measures. The paper also supports that the success of bicycle usage is dependent on both political will and resolve and on a comprehensive, integrated and long range approach where the involvement and commitment of people, public and private actors is of extreme importance.

\section{Theoretical Framework}

Although several definitions are provided by experts and academics, they all possess as common feature the fact that 'cycling policies' represent a package of strategies and actions which are specifically devised to increase bicycle commuting [1]; [2]. For some experts such definition should also highlight the importance of safety conditions when commuting [3]; [4]. Additional variations were also verified, focusing either on travel distances (shorter trips), cycling uses (utilitarian and / or recreational), provision of cycling facilities (bikeways and parking), and car restrictive measures [5]. Although different in content all definitions are in fact relatively similar in concept. Cycling policies can be categorised in four different yet complementary topics: physical, soft, complementary and knowledge policies. Physical policies focus on infrastructural measures and are an indispensable first step in encouraging cycling by providing cycle friendly facilities and developing cycle routes and networks [5]; [6]. Coordinated with physical policies, soft policies have proven effective in stimulating people to commute by bicycle [5]; [6]; [7]; [4]. These are intangible measures intended to bring about behavioural change by publicizing infrastructure improvements and availability, promoting travel awareness, information, special events, training and education programmes. Complementary policies should also be considered, namely those intended to restrict or hamper car use and circulation, discourage car purchase, adopt cycle friendly regulations, design mixed-use communities and transit oriented projects that facilitate the proximity of residential areas to transport hubs, local amenities, commercial and service centres [7]; [4]. Also, the adoption of bicycle use by certain visible professions, such as postal carriers and the police in addition to local government leaders, may contribute to increase cycling visibility and credibility. Knowledge policies which emphasize the role of investment in research and development towards sustainable mobility should also be considered [5]. Such policies and measures are most effective when developed and executed at Municipal levels, particularly if spatial dimension and territorial dispersion of urban areas is not overlooked in the process, since promoting bicycle commuting in large cities is considerably more challenging than in small cities and cycling rates tend to be significantly higher near centre and historic urban areas in opposing to outer neighbourhoods [8]. At higher levels (Supra-National, National and Regional), such measures focus mostly on establishing general goals, providing dedicated funding and continued cooperation with lower levels of government. The development of policies and measures should be cross-referenced with different government levels and spatial dimensions by ensuring that considered planning systems achieve both vertical and horizontal integration, namely, governmental cooperation and spatial consistency and coherence [8]; [9]. Regarding their nature, one can consider two distinct yet complementary solutions to achieve a modal shift from commuting by car to bicycle usage [6]. Push measures or 'sticks', developed with the intent to persuade people away from car usage by making driving less attractive (allowing to improve cycling competitiveness regarding car travel), and pull measures, or 'carrots', aimed at creating alternative mobility solutions, such as bicycle commuting, enhancing safety, convenience and comfort of bicycle users [5]; [6]. Policy combination theory considers that the effects of policies increasingly reinforce each other, so that the total effect of a policy package is larger than the sum of their effects if applied separately [10]. Nonetheless, push measures appear to have stronger impacts than pull measures in bicycle development [11]. Regarding their implementation process, long-run procedures are frequently used when employing 'push' policies and measures. Given their sensitive and challenging nature they require careful planning and promotion resulting in a more time-consuming development. On the other hand, short-run procedures, which are usually associated to the implementation of pro-bicycle actions (pull measures), provide a swifter process due to their more direct and less challenging character [2]. The successful 
implementation of such policies and measures often depends on strong leadership and adequate capability of authorities to integrate the necessary elements for overcoming existent 'traditional barriers' and 'cultural attitudes' on cycling [3]; [11]; [12].

\section{Case Study}

Lisbon's cycling network evolution has two distinct moments. The first moment, which began during the year 2000, was a lengthy and complex process. In seven years merely $14 \mathrm{~km}$ of routes were built, namely in Monsanto Park, to the west of the city, in the Campo Grande urban park, located in Lisbon's central area, in Telheiras located to the north, and in the Parque das Nações area, located northeast of the city. In 2007, Lisbon was a city without cyclists despite all created paths, making it difficult to justify a continued commitment in this type of infrastructure. Nonetheless, the Municipality resiliently continued to focus on its network continuity and evolution, reinforcing its development dynamic. Between 2008 and 2009 Lisbon expanded the network in approximately $24 \mathrm{~km}$, an increase of approximately 170\% regarding the first seven years. Between 2010 and 2014, approximately $26 \mathrm{~km}$ of new routes were added to the city, namely the river link between the area of Parque das Nações and the downtown historical area. Overall, during 14 years, little over $63 \mathrm{kms}$ of cycling network were developed. In this first phase, which according to the Municipality can be considered as an experimenting phase, the network was developed using a more conservative approach focused on users unaccustomed to travel by bicycle, especially in a system dominated by motorized vehicles and the focus was in establishing connections between existing green areas and important amenities and infrastructures such as public transport interfaces and university areas. In the second moment, which started in 2015, a different approach was considered. In addition to the devise of the city's cycling network, the development of bicycle routes gained a fresh momentum and started displaying a different concept with most of all new bicycle routes sharing the road with motorized vehicles. Whenever possible, segregated routes were created, particularly in areas with higher traffic volume, intensity and speed. During this second phase, the Municipality intends to create little over 90 kms of new bicycle routes across 142 streets and approximately $70 \%$ of such routes will be completed between 2015 and 2019 (Fig. 1a). Considering this new strategic framework, one that envisions the bicycle as a mobility solution supportive of the public transportation system and focused on utilitarian cycling, a new network layout was designed with the clear intent of increasing bicycle share. This moment, which one could say corresponds to an assertion and expansion phase, is also characterized by an enhanced focus in user's requirements, regardless of their age, gender or experience, and a new hierarchical organisation system that considers three levels: Fundamental; Complementary; and Local. The fundamental network, representing approximately $43 \%$ of the overall network, is intended to enable daily commutes between the city's different 'core areas' and neighbouring municipalities such as Amadora, Odivelas, Oeiras, Loures and Almada. Considering such agenda, the bicycle routes need to ensure safe, comfortable and functional travels to its users so that they can commute quickly and efficiently. The complementary network (26\% of the total network) has the key purpose of establishing connections between the fundamental and the local network and to important amenities (public transport interfaces, university centres and cultural facilities, among others.) in addition to social, commercial and service areas. The local network, representing approximately $31 \%$ of the overall network, is intended to ensure home to work connections, while also enabling easier access to local commercial and service activities (Fig. 1b). Regarding route typology (Figs. 1c and 1d), the preferred adopted solution is bicycle tracks, representing approximately $56 \%$ of all the envisioned network. This typology corresponds to a unidirectional or bidirectional route, which is segregated from motorized traffic by using physical separation. The bidirectional solution is the most represented of this typology with a total share of $84 \%$. The second preferred typology is shared lanes. Such typology represents approximately $29 \%$ in the cycling network. In such routes bicycles share the road space with motorized vehicles which have a speed limit of $30 \mathrm{~km}$ per/hour and are obligated to give priority to bicycle traffic. In cases of one way traffic streets it is also considered a small bicycle route parallel to motorized traffic, allowing the bicycle to travel in counter-flow, provided that adequate security conditions are ensured. Bicycle lanes, with $7 \%$ of the network representation, do not have a proper physical separation with road spaces. Such 
separation is ensured mostly by recurring to visual differentiation and signalling. It is a route that is neither segregated or shared and is exclusively unidirectional. Another typology is mixed streets with a representation of $8 \%$ of the city's bicycle network. In such typology street space is shared both with pedestrians, bicycle users and with motorized vehicles. In addition to a speed limit of $20 \mathrm{~km}$ per/hour, pedestrians and bicycle users have movement privileges over motorized transportation. Lastly, the type identified as bicycle trail represents recreational and sport paths located in Monsanto's park. For that reason, despite its nearly $40 \mathrm{~km}$ of extension, such typology is not included in the network's total extension.

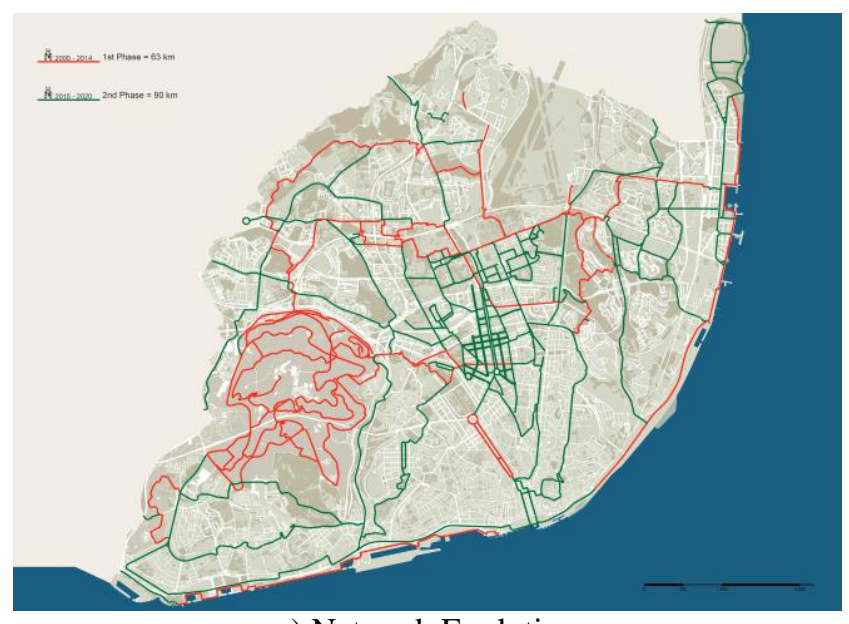

a) Network Evolution

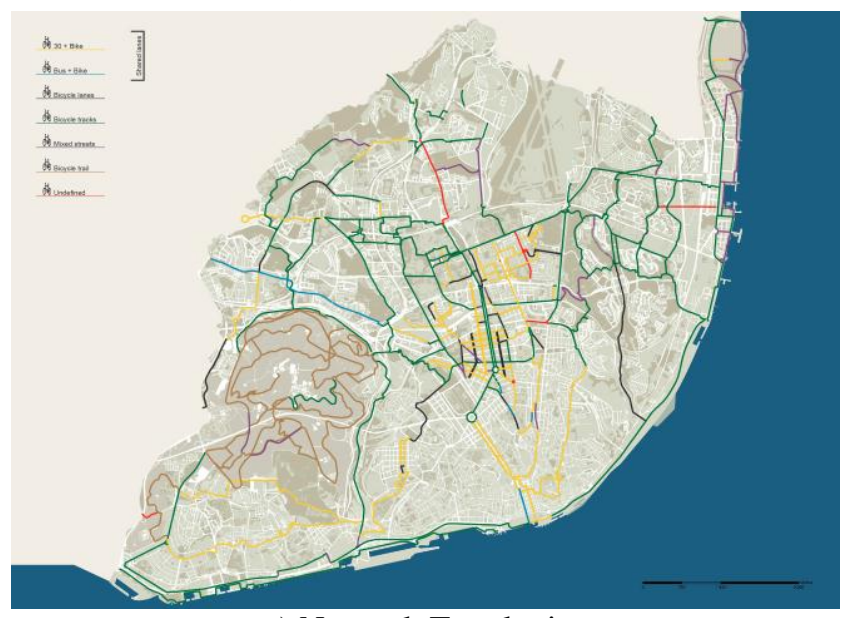

c) Network Typologies

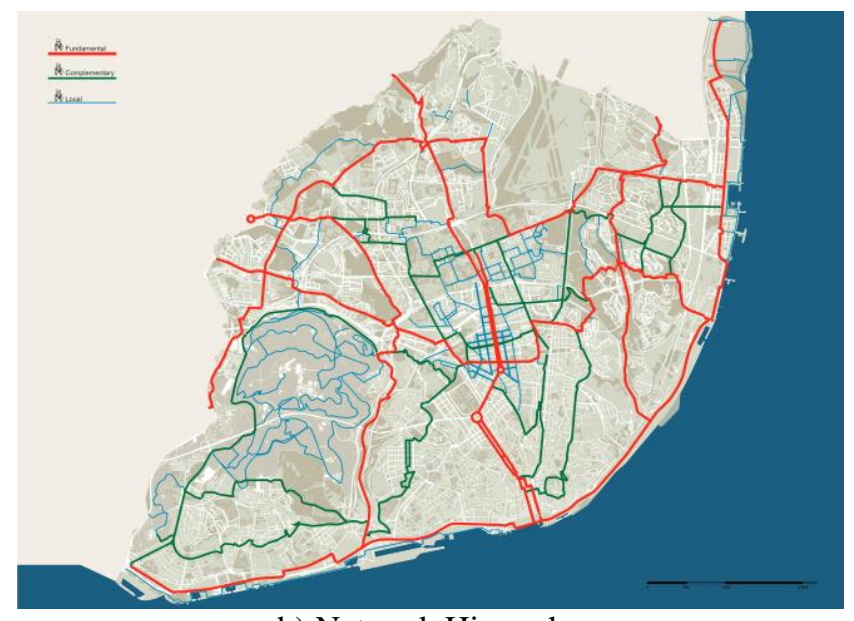

b) Network Hierarchy

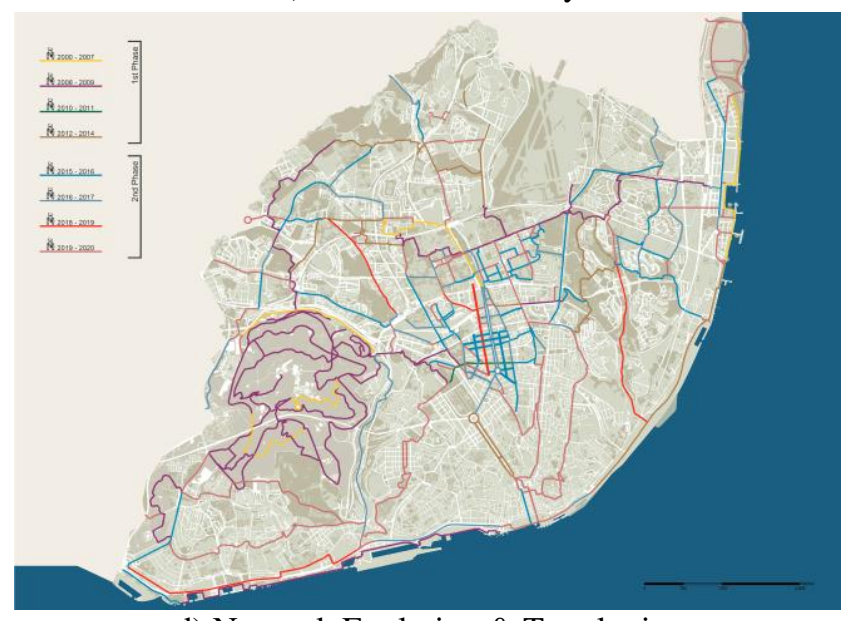

d) Network Evolution \& Typologies

Fig. 1: Lisbon's Cycling Network (Adapted from CML, 2016).

Regarding developed policies and measures (Table I), they focus on physical policies (infrastructure), namely: Routes and links design, including several elevated connections; Intersection design, focusing on safety and reducing stop periods for users; Parking solutions, although additional focus is needed regarding the creation of sheltered and guarded parking solutions; and Public transportation, such as allowing users to travel with their bicycles on trains, subways and buses in addition to creating parking facilities at stops and interchanges. Concerning complementary policies, present attention is in the implementation of a bike share system, which upon completion will have an estimated offer of 1.410 bicycles, most of them electric, distributed by 140 stations. Traffic calming measures, mixed streets, improving public transportation frequency, and creating parking areas near city's entrances are also being considered. The creation of management policies and measures regarding urban logistics and tourism shuttle transportation is also being assessed. 
TABLE I: Considered Policies and Strategies for Lisbon's Network

\begin{tabular}{|c|c|c|c|c|c|c|}
\hline & & Measures & Push & Pull & Long-run & Short-run \\
\hline \multirow{22}{*}{ 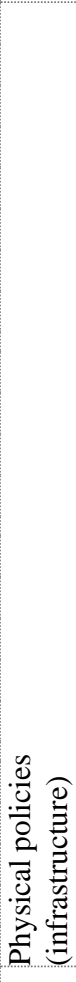 } & & Bicycle tracks & & $\bullet$ & & $\bullet$ \\
\hline & & Bicycle lanes & & $\bullet$ & & $\bullet$ \\
\hline & & Contra-flow bicycle lanes & & $\bullet$ & & $\bullet$ \\
\hline & $\underline{y}$ & Bicycle streets & & $\bullet$ & & $\bullet$ \\
\hline & $\Xi$ & Shared lanes (with traffic, buses and pedestrians) & & $\bullet$ & & $\bullet$ \\
\hline & $\infty$ & Bicycle trails & & $\bullet$ & & $\bullet$ \\
\hline & $\stackrel{\varrho}{=}$ & Bicycle advanced stop lines & & $\bullet$ & & $\bullet$ \\
\hline & $\stackrel{2}{2}$ & Bicycle turn boxes & & $\bullet$ & & $\bullet$ \\
\hline & $\tilde{\approx}$ & Right-of-way & & $\bullet$ & & $\bullet$ \\
\hline & : & Roundabouts & & $\bullet$ & & $\bullet$ \\
\hline & $\stackrel{\infty}{0}$ & Traffic-light & & $\bullet$ & & $\bullet$ \\
\hline & $\stackrel{\mathscr{E}}{\Xi}$ & Crossings (street level and elevated) & & $\bullet$ & & $\bullet$ \\
\hline & & Sheltered & & $\bullet$ & & $\bullet$ \\
\hline & & Unsheltered & & $\bullet$ & & $\bullet$ \\
\hline & 0 & Guarded & & $\bullet$ & & $\bullet$ \\
\hline & 的 & Lockers & & $\bullet$ & & $\bullet$ \\
\hline & בี & Private (workplaces, residences, malls ...) & & $\bullet$ & & $\bullet$ \\
\hline & $\overline{0}$ & Bicycle facilities at transport stops and interchanges & & $\bullet$ & & $\bullet$ \\
\hline & ह & Bicycle racks on buses & & $\bullet$ & & $\bullet$ \\
\hline & $\Xi$ & Bicycle racks on trams and subway & & $\bullet$ & & $\bullet$ \\
\hline & $\because \frac{0}{0}$ & Bicycle racks on trains & & $\bullet$ & & $\bullet$ \\
\hline & $\vec{z}$ & Bicycle racks on boats & & $\bullet$ & & $\bullet$ \\
\hline \multirow{13}{*}{ 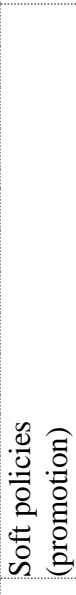 } & & Promotional campaigns & & $\bullet$ & & $\bullet$ \\
\hline &. & Events and festivals & & $\bullet$ & & $\bullet$ \\
\hline & 䘜 & Travel awareness programs & & $\bullet$ & & $\bullet$ \\
\hline & $\stackrel{0}{=}$ & Specific programs (bike to work and school days ...) & & $\bullet$ & & $\bullet$ \\
\hline & & Wayfinding signage & & $\bullet$ & & $\bullet$ \\
\hline & $\approx$ & Information centers & & $\bullet$ & & $\bullet$ \\
\hline & 胥 & Bicycle routes map distribution & & $\bullet$ & & $\bullet$ \\
\hline & हี & Trip reduction programs & & $\bullet$ & & $\bullet$ \\
\hline & $\Xi$ & Safe routes to school & & $\bullet$ & & $\bullet$ \\
\hline & & Child learning and safety programs & & $\bullet$ & & $\bullet$ \\
\hline & .ే & Adult learning and safety programs & & $\bullet$ & & $\bullet$ \\
\hline & 氖 & Bicycle testing events & & $\bullet$ & & $\bullet$ \\
\hline & F & Motorist training and education & & $\bullet$ & & $\bullet$ \\
\hline \multirow{10}{*}{ 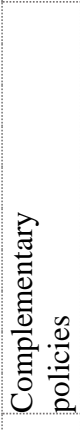 } & & Bicycle Sharing & & $\bullet$ & & $\bullet$ \\
\hline & & Restrict car use (congestion charging reduce parking availability) & $\bullet$ & & $\bullet$ & \\
\hline & & Increase car parking cost & $\bullet$ & & $\bullet$ & \\
\hline & & Cycle friendly traffic regulations & $\bullet$ & & $\bullet$ & \\
\hline & & Traffic calming & & $\bullet$ & & $\bullet$ \\
\hline & & Car free zones & & $\bullet$ & & $\bullet$ \\
\hline & & Mixed streets & & $\bullet$ & & $\bullet$ \\
\hline & 0 & Improve public transportation & $\bullet$ & & $\bullet$ & \\
\hline & & Design mixed-use communities & $\bullet$ & & $\bullet$ & \\
\hline & $\ddot{a}$ & Transit oriented development projects & $\bullet$ & & $\bullet$ & \\
\hline \multirow{4}{*}{ 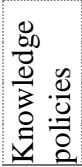 } & & Research and development & & $\bullet$ & & $\bullet$ \\
\hline & & Bicycle counters & & $\bullet$ & & $\bullet$ \\
\hline & & Bicycle traffic analysis (loop detectors or direct observation) & & $\bullet$ & & $\bullet$ \\
\hline & 党 & Bikeability assessment & & $\bullet$ & & $\bullet$ \\
\hline
\end{tabular}


Knowledge policies, namely installation of additional bicycle counters in the city, focusing on its centre areas, and partnering with local universities with the intent of analysing cycling's evolution are also being deployed. However, soft policies are being overlooked, either regarding the number or frequency of promotion, information and education actions and events. Such actions, namely learning and safety programs, events and festivals, safe routes to school, bike to work days, are being mostly driven by private cycling advocacy organizations working in collaboration or with the endorsement of the Municipality, corroborating the important and active role that such groups have in campaigning for cycling.

\section{Conclusion}

The findings, suggest that such 'cycling policies' can be defined as a package of programmes and measures, used both by public authorities and private stakeholder's, establishing direct and indirect strategies, actions and rules of procedure to increase and encourage cycling as a secure, comfortable and attractive mobility solution, regardless of its purpose (utilitarian or recreational). Such policies are most effective when developed and executed at a local level, particularly if spatial dimension and territorial dispersion of urban areas is not overlooked in the process. At higher levels, such measures focus mostly on establishing general goals, providing dedicated funding and continued cooperation with lower levels of government. The development of policies and measures should be cross-referenced with different government levels and spatial dimensions by ensuring that considered planning systems achieve both vertical and horizontal integration, namely, governmental cooperation and spatial consistency and coherence [8]; [9]. In addition, results also suggest that cycling policies and measures may possess distinct, yet complementary, forms and natures, devised with the intent to implement 'encouraging and discouraging actions' to promote bicycle commuting, during a particular period, preferably including a tailored mix of short and long-run procedures. Such an effective and integrated implementation requires interactive and participatory processes, where the involvement and commitment of people, public and private actors is of great importance in raising society's awareness regarding sustainable urban mobility, namely bicycle commuting. Our findings also reveal that Lisbon's cycling network was developed considering a medium to long term political agenda with the intent of promoting bicycle commuting as a 'new' solution in urban mobility, one that needs to be carefully integrated with the city's present and future transport system. This was a complex process, made of forward and backward movements, which involved substantial negotiation, mostly at a governmental level, regarding its concept, route typology and implementation procedures. In addition to information gathering, different spatial and social analysis were developed and different scenarios were assessed by the Municipality prior to the conclusion of the current network layout. By 2020, $90 \mathrm{~km}$ 's of new cycling routes will be created, focusing on the network's fundamental and complementary hierarchic levels, representing an increase of approximately $140 \%$ regarding its first phase. In addition to its extension, a different approach is also being introduced, focusing on utilitarian cycling and presenting a new hierarchical system. The network favoured route solution is bicycle tracks, namely bidirectional tracks, followed by shared lanes. By cross referencing the network's hierarchy with the envisioned typologies, one can observe that in the fundamental network the preferred type of route is the bicycle track, representing $75 \%$ of the existent/considered routes for this hierarchy level, followed by shared lanes with a $16 \%$ representation. In the complementary level the preferred solution is shared lanes, representing $53 \%$ of the hierarchical level, followed by bicycle tracks with $36 \%$. The local level preferred route type is the bicycle track with a $45 \%$ representation, followed by shared lanes with $26 \%$ and mixed streets with $22 \%$. Such options can be understood as clear evidence of the commitment of the Municipality in providing safe routes to its users. Nevertheless, the key question centres on the extent to which the envisioned goals are being fulfilled, and in that regard the results do not disappoint. In addition to direct observation analysis, such finding is supported by results presented by Lisbon's existent bicycle counter located in one of the city's centres, which allows us to conclude that regarding a three-month period (February to April), 2017 values reveal a 60\% increase in cycling journeys regarding 2016. As for policies and measures, our findings establish that the network's focus has been on physical measures overlooking soft measures such as communication and information events, making it more challenging to 
campaign for cycling. It is expected that the launch of Lisbon's bike share system may reverse such scenario. Also, more specific objectives should have been presented instead of a single general goal such as 'increase cycling'. Establishing a bicycle share value to be achieved during a timeframe would allow to more accurately assess if the intended objectives were being met and why. The inexistence of a strategic report that sets overall goals, details policies and actions to be achieved during a specific timeframe and provides for a comprehensive, coordinated and integrated approach makes it difficult to recognize Lisbon's cycling network as an effective planning and compliance tool. By 2020, Lisbon's cycling network will have nearly $160 \mathrm{~km}$ of routes, mostly built during its second phase, a clear demonstration of the Municipality's intent and resolve in promoting cycling as a valid and viable solution regarding the city's future mobility system and environmental agenda.

\section{Acknowledgements}

The authors are thankful to the Municipality of Lisbon, explicitly to the Deputy Mayor's offices responsible for Green Structure and Energy and Urban Planning and Public Space, for providing and allowing the use of information regarding Lisbon's cycling network.

\section{References}

[1] R. Buehler and J. Dill, "Bikeway Networks: A Review of Effects on Cycling," Transport Reviews, 36:1, pp. 9-27, November 2016.

[2] R. B. Noland and H. Kunreuther "Short-run and long-run policies for increasing bicycle transportation for daily commuter trips," Transport Policy, 2:1, pp. 67-79, 1995.

[3] J. Pucher, R. Buehler and M. Seinen, "Bicycling Renaissance in North America? An Update and Re-Appraisal of Cycling Trends and Policies," Transportation Research Part A, vol. 47, pp. 451-475, March 2011.

[4] J. Pucher, J. Dill and S. Handy, "Infrastructure, programs, and policies to increase bicycling: An international review," Preventive Medicine, 50, pp. 106-125, January 2010.

[5] G. Santos, H. Behrendt and A. Teytelboym, "Part II: Policy instruments for sustainable road transport," Research in Transportation Economics, 28:1, pp. 46-91, 2010.

[6] T. Riley, "Translating cycling policy into cycling practice," World Transport Policy \& Practice, 7, pp. 38-43, 2001.

[7] J. Pucher and R. Buehler, "Promoting Cycling for Daily Travel: Conclusions and Lessons from across the Globe," in City Cycling, J. Pucher \& R. Buehler, Cambridge, Massachusetts: MIT Press, 2012, ch. 15, pp. 347-363.

[8] R. Buehler and J. Pucher, "Big City Cycling in Europe, North America, and Australia," in City Cycling, J. Pucher \& R. Buehler, Cambridge, Massachusetts: MIT Press, 2012, ch. 13, pp. 287-318.

[9] D. Banister, S. Marshall, and A. May, “A Research Agenda," in Land Use and Transport: European Research Towards Integrated Policies, S. Marshall and D. Banister, Bingley: Emerald Group, 2007, ch. 17, pp. 375-386.

[10]K. Lautso and M. Wegener, "Integrated Strategies for Sustainable Urban Development," in Land Use and Transport: European Research Towards Integrated Policies, S. Marshall and D. Banister, Bingley: Emerald Group, 2007, ch. 8, pp. 153-176.

[11]D. Blackledge, A. May, and M. Wegener, "Lessons for Policy," in Land Use and Transport: European Research Towards Integrated Policies, S. Marshall and D. Banister, Bingley: Emerald Group, 2007, ch. 16, pp. 365-374.

[12]P. Rietveld and V. Daniel, "Determinants of bicycle use: do municipal policies matter? ," Transportation Research Part A: Policy and Practice, 38:7, pp. 531-550, May 2004. 